\title{
How a nimble company switches business model
}

\section{Discovering strategic agility's fit with SMEs' needs}

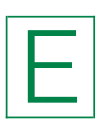

urofirms a family-owned temporary work agency, at first served mainly local firms. It was founded in Girona, Spain in 1991. At the time, the industry was growing at an average annual rate of 6 per cent, and the large multinational temporary work agencies were entering the Spanish market. Eurofirms' geographical growth began with the opening of offices in Barcelona in 2001 and other nearby locations, then other regions of Spain and, in 2013, operations began in Portugal.

Between the late 1990s and 2007 approximately, the market was "demand driven". The need for temporary agency workers was high in comparison to supply, commercial margins were wide and price and volume were important - but not critical - variables in the industry. This allowed large and small temporary work agencies (TWAs) in the sector to coexist. However, from 2008 the industry changed dramatically. Demand slowed down considerably and commercial margins noticeably narrowed.

Price then became the crucial decision variable for customer firms, and a high turnover was needed to cover costs and stay in the market. This was a deadly challenge for many small TWAs, with adaptation of business models gaining importance. Eurofirms engaged in organic growth and also acquired several small TWAs. Eventually becoming the fourth leading firm in the industry in terms of its turnover and the first with Spanish ownership.

Eurofirms business model (BM) is that of partial customization; customer satisfaction is pursued by customizing services to address the real needs of customers, assuring precision, reliability, and trust. Customer satisfaction is enhanced by counting on engaged temporary workers who are motivated by transparency and proximity. Eurofirms' employees, in turn, are customer-oriented, particularly with regard to service, reliability, and trustworthiness. Customers feel satisfied, and they trust Eurofirms and respond with loyalty.

Resource fluidity, leadership unity, and strategic sensitivity

Overheads are constrained by means of centralizing technical expertise, for instance legal and regulatory matters (the part of the service that is not customized), risk management, and technological development. Staff costs are optimized by means of the proactive and committed behavior of employees and flexible task management.

Eurofirms' BM has the advantage of being adaptive to the new context of economic slowdown and has managed to both improve added value for clients and to reduce costs. Thus, it has remained attractive to the market segments that need or appreciate the added 
value and at the same time require a competitive price. The basic BM of Eurofirms is fine-tuned to sustain and renew its competitiveness. More specifically, the firm deploys its business model innovation (BMI) along three dimensions: value proposition, value-chain, and cost and revenue models.

In an analysis of how the special dynamic capabilities underlying strategic agility fit the small and medium-sized enterprise (SME) context in the case of a service firm specifically, the case study organization - Arbussa et al. (2017) of the University of Girona, were able to identify the constructs of change in the business model, the capabilities, and the meta-capabilities. They found that resource fluidity and leadership unity were the two meta-capabilities present. Due to their presence and quantity, they are described as inherent, being integral, and strongly driven by the nature and characteristics of SMEs.

\section{Closer to an art form than a science}

Strategic agility is defined as an organization's capacity to make strategic commitments while staying nimble and flexible and is considered to be a means by which they transform and reinvent themselves, adapt and ultimately survive. Leadership unity is "the ability of the top team to make bold, fast decisions, without being bogged down in top-level "win-lose" politics". And, resource fluidity is described as "the internal capability to reconfigure capabilities and redeploy resources rapidly".

A third meta-capability - strategic sensitivity - was also present in the case study, and the authors argue that it has a critical nature in Eurofirms. Strategic sensitivity is defined as "the sharpness of perception of, and the intensity of awareness and attention to, strategic developments". In the case study, strategic sensitivity was found to be closely dependent on the general manager as an individual. The authors also argue for the presence of a fourth meta-capability - resourcefulness - as an SME-specific capability, which is broadly defined as the ability to overcome inherent limitations (mainly in terms of human and financial resources).

The case also illustrates that the different meta-capabilities have an ordered deployment after minimum threshold levels in each meta-capability are achieved. In other words, the components of strategic agility may not act homogeneously across time. This finding suggests a dynamic view of strategic agility in the sense that different underlying capabilities are needed at different strategic stages.

\section{Creative problem-solving to cope with financial limitations}

The authors note that, despite a consensus on the relevance of BM innovation, designing a new business model is considered to be closer to an art form than to a science, because of the complex interconnections between the elements; the unpredictable, fuzzily delimited and fast-moving environment; and the lack of data or knowledge to detect and predict the future. An SME owner's fear of the unknown, lack of trust and cultural or age conservatism can result in reluctance to change.

By definition, being an SME implies having some characteristics that affect the quantity, and sometimes the quality, of some resources in comparison to a large company. For example, Eurofirms, like many other SMEs, tends to have less financial capability, including less ability to raise capital, particularly in comparison to the multinational sector leaders.

\section{Strategic sensitivity was found to be closely dependent on the general manager as an individual.}

PAGE 12 STRATEGIC DIRECTION | VOL. 33 NO. 72017 


\section{An SME owner's fear of the unknown, lack of trust and cultural or age conservatism can result in reluctance to change.}

However, this was not a barrier to growth. Eurofirms used organic growth, following customer demands across Spain as a whole, and engaged in several acquisitions, where Eurofirms leased the new companies at rental price over a period, instead of acquiring them in their entirety.

\section{Motivation, competence development and employees' goal alignment}

This is an example of creative problem-solving to cope with financial limitations - an example of resourcefulness. Furthermore, this means having the great agility to change systems to incorporate the newly acquired companies without endangering the existing BM. Resourcefulness has been defined in some of the literature for SMEs - as a set of resources (financial, social and tangible) and capabilities (strategic and operational flexibility) that are key enablers of resilience and performance (sales, cash flow and ultimately profitability). The lack of resources in SMEs could also be considered in terms of the quantity and maybe the quality of some staff, especially of highly qualified workers.

This type of weakness is overcome through motivation, competence development and the goal alignment of the firm's employees, which leverages their strengths.

Another limitation of Eurofirms, and of SMEs in general, is that they can take less advantage of economies of scale in comparison to larger competitors. However, Eurofirms managed to minimize this problem by increasing its size through organic growth and acquisitions and offering customized services for which economies of scale are not relevant.

\section{Comment}

Keywords:

This review is based on "Strategic agility-driven business model renewal: the case of an SME" by Arbussa et al. (2017). Basing their research on a case study of a Spanish-based firm supplying temporary workers, the authors connect strategic agility and business model innovation and explore how capabilities underlying strategic ability fit the SME context.

Business model, SME,

Business model innovation, Temporary work, Strategic agility

\section{Reference}

Arbussa, A., Bikfalvi, A. and Marquès, P. (2017), "Strategic agility-driven business model renewal: the case of an SME”, Management Decision, Vol. 55 No. 2, pp. 271-293.

For instructions on how to order reprints of this article, please visit our website:

www.emeraldgrouppublishing.com/licensing/reprints.htm

Or contact us for further details: permissions@emeraldinsight.com 